\title{
MICHEL TOURNIER
}

\section{Isabelle Eberhardt o la metamorfosis consumada ${ }^{*}$}

Gan Petersburgo durante los últimos resplandores del zarismo. $\$$ El general Carlowitch von Moerder decide contratar un preceptor para Nicolás, Nathalie y Vladimir, los tres hijos de su matrimonio con Nathalie Dorortée Eberhardt de soltera. El preceptor se llama Alexandre Trophimowsky; "Vava" para los amigos íntimos. Tiene cuarenta y cuatro años. Es un pope armenio que ha colgado los hábitos para convertirse al socialismo; posee una cultura enciclopédica y una enorme vocación al vodka. Prónto juzga más interesante convertir a Nathalie Dorotée a sus ideas que enseñarles griego y latín a sus alumnos. Lo hace tan bien que la seduce y luego la rapta con sus tres hijos, dejando en San Petersburgo a su mujer, a sus hijos...y al general Von Moerder, que no se explica el repentino vacío a su alrededor. Sin embargo, sigue la pista de los fugitivos y los alcanza en un hotel de Nápoles. Se producen homéricas disputas entre el ex pope y el marido burlado. Vava, quien profesa la libertad sexual, concede generosamente a los Von Moerder su última noche conyugal; al día siguiente el general regresa en tren a San Petersburgo. Muere un año después y deja una herencia bastante conflictiva, pero que permite a los inmigrantes establecerse. Así, en 1872, Vava, Nathalie y los niños - que son ya cuatro por el nácimiento del pequeño Augustín- se instalan en Meýrin, cerca de Génova, en una quinta a la que se le da pronto el nombre de "tropical", por. que el ex pope se afana en cultivar cactus en su jardín. En febrero de 1877, Vava viaja a San Petersburgo para poner en orden la herencia del general. Durante su ausencia, Nathalie da a luz a su quinto hijo, una niña que recibe el nombre de Isabelle Wilhelmine.

¿De quién es hija Isabelle Eberhardt, cuya vida novelesca da

\footnotetext{
* Del libro de ensayos literarios de Michel Tournier titulado El vuelo del vampiro, de próxima aparición con el sello del Fondo de Cultura Económica. (Traducción de José Luis Rivas).
} 
comienzo con un misterio? En su libro consagrado a Rimbaud, ${ }^{1}$ Pierre Arnoult atribuye sin rodeos la paternidad de Isabelle al autor de "El barco ebrio". Para ello se basa en tres indicios, por lo demás muy frágiles: el parecido físico entre Isabelle y Rimbaud; la presencia de Arthur en la región del lago Léman en junio de 1876; el nombre de la recién nacida, Isabelle Wilhelmine, inexplicable por el lado de los Moerder-Trophimowsky, pero vinculado por parte de Rimbaud con su hermana preferida y con la reina de Holanda, en cuyo ejército acaba de alistarse. Françoise d'Eaubonne, en su excelente biografía de Isabelle Eberhardt, ${ }^{2}$ añade a dichos indicios un misterioso juramento, avalado por el testimonio de varias personas: "Yo moriré convertida en musulmana como mi padre". Desde luego, no se trata de Trophimowsky y no podemos sino asombrarnos del extraño tropismo que el Islam obra en los destinos de Rimbaud y de Isabelle Eberhardt. Una y otro fueron sinceros conversos. Isabelle Rimbaud cuenta que su hermano, al agonizar, recitó la plegaria Allah kermin.

Era preciso mencionar, desde luego, esta hipótesis de Pierre Arnoult, que evidencia un romanticismo descabellado; no obstante, la audaz y genial Isabelle Eberhardt no tenía necesidad de ese parentesco extraordinario.

Si Trophimowsky no es el padre consanguíneo de Isabelle, sin duda es su hija espiritual. El ex pope educa a sus cinco hijos en ruso, francés y alemán; los somete a una presión espiritual abrumadora, febril, agitada, con el auxilio de una enorme y extravagante biblioteca. Por supuesto, el ambiente de la quinta tropical nada tiene de apacible. Un día, Nathalie, la hija mayor, se fuga con un oficial en medio del aluvión de maldiciones que profiere su padre. Después, Vladimir, uno de los dos mediohermanos de Isabelle, se suicida con gas. Más tarde Nicolás retorna a la Santa Rusia. Isabelle se queda con su otro mediohermano, Augustín, con el que está unida como a su alter ego. ¿A quién se parece Isabelle cuando es adolescente? Un visitante refiere:

Mucho había oído hablar del maravilloso jardín de Trophimowsky. Me hice de una carta de presentaclón y fui a visitarlo. En el patio un muchacho partía leña. Alto, airoso, parecía de dieciséis años. La cara

\footnotetext{
${ }^{1}$ Edit. Albin Michel.

${ }^{2}$ La Couronne de sable, Edit. Flammarion.
} 
redonda, un poco como luna llena, imberbe, los cabellos negros. Era Isabelle Eberhardt, aunque no lo advertí a primera vista. " $\mathrm{cHa}$ visto a mi hija?", me preguntó Trophimowsky. "Se viste como si fuera un hombre; le resulta más cómodo para ir a la ciudad". 'Padre e hija formaban una pareja extraordinaria! Culto, inteligente, feroz enemigo de cualquier disciplina, el ex pope sentía aversión por la Biblia. "iJesucristo, canalla!", profería a cada momento, asestando un puñetazo en la mesa.

En 1894, Augustín se fuga a su vez. La primera carta que su hermana recibe está fechada en Sidi Bel Abbas: el hijo del general Von Moerder se ha convertido en legionario. Para su padre el suceso es un síntoma de decadencia; para Isabelle es una llamada. Hace años que aprende árabe. Cada carta de su hermano predilecto va madurando su decisión. Sólo su madre la retiene allí. En mayo se decide a partir...llevándola consigo.

Las dos mujeres se establecen en la ciudad de Bone, en Argelia. Para Isabelle aquello es la plenitud. Vestida como hombre, se desenvuelve a sus anchas en la comunidad indígena. Pero su madre no resiste el desarraigo y muere, Trophimowsky acude puntual a enterrarla. En esa misma época, André Gide escribe El inmoralista, historia de un hombre que alcanza la salud moral y la felicidad física en esa misma Argelia, cuyo clima no soporta su mujer y muere en Touggour, dejándolo libre y feliz. Vamos a encontrar esta afinidad en André Gide e Isabelle Eberhardt.

$\mathrm{Su}$ vida transcurrió entonces en un perpetuo vaivén entre África y Europa. Ella sólo aspira a compenetrarse cada vez más íntimamente con ese Islam magrebiano; pero nada es fácil. Para el gobierno francés es motivo de recelo esa mujer rusa con nombre alemán, vestida como un hombre, que sólo frecuenta los medios "indígenas" y vive, además, constantemente apremiada por problemas económicos.

Pero ella prosigue su metamorfosis. Adopta el nombre de Mahmoud Essadi. Recibe la investidura de los kadryas, una poderosa secta musulmana. Cierto día se une como "escribano" a una pequeña caravana, a la cual las autoridades tunecinas han encomendado hacer averiguaciones sumarias y recabar impuestos. Su jefe es un joven califa de Monastir. Lo acompañan dos viejos notarios árabes de un destacamento de espahíes.

Y a continuación, el drama. El 29 de enero de 1901, en 
Béhim, un fanático de una secta enemiga - los tidjanyas- intenta asesinarla. Herida de dos sablazos, es operada y curada en el hospital Militar de El-Oued. Cuando su agresor es juzgado por el consejo de guerra de Constantine, Isabelle escandaliza a jueces $\dot{y}$ testigos asumiendo ardorosamente su propia defensa, sin ocultar nada acerca de su vida y sus creencias. El veredicto es terrible. Para el culpable, trabajos forzados a perpetuidad; para la víctima, la expulsión. iNo es otro el precio que debe pagar una vida emancipada e insolente que se enfrenta a las costumbres y al régimen militar!

Isabelle se aburre en Marsella. No por mucho tiempo. Se casa con un argelino musulmán, suboficial de los espahíes. De esa manera adquiere la nacionalidad francesa y nadie puede impedirle que vuelva a Argelia. Pero su desafio a las autoridades no le facilita las cosas.

Su errancia por el desierto, los ueds, los oasis, se reanuda. iNo será el matrimonio el que estabilice a esta nómada inveteradạ! Isabelle hace suya, subrayándola, esta frase del mariscal de Sajonia: "No hay que vivir, sino partir". Otra vez provoca escándalos esta musulmana vestida como caballero árabe, que pasa la noche en el aduar, se sienta a la mesa de los jornaleros con el cigarrillo en los labios, y bebe y blasfema como un cosaco.

Esta febril carrera tiene un trágico desenlace el 21 de octubre de 1904, en la ciudad de Aïn-Sefra, a la que Isabelle amaba como el primer ksar del Sáhara, verdadera puerta del desierto: una tempestad de apocalíptica violencia transforma las calles bajas de la ciudad en un furioso torrente de barro amarillento. Las casitas son barridas junto con sus habitantes. Isabelle saca a su marido, regresa por un manuscrito y cuando trata de salir nuevamente, la casa se derrumba sobre ella. Su cuerpo fue encontrado entre los escombros varios días depués. Tenía veintisiete años.

Isabelle Eberhardt no publicó nada en vida, pero sus obras son un testimonio admirable del África blanca de principios del siglo. Esta obra - forzosamente muy breve- ocupa un lugar destacado entre las obras de autores occidentales que fueron atraídos poderosamente por el Islam, y que trataron, con mayor o menor fortuna, integrarse a él. Respecto a Isabelle, a menudo se ha mencionado a André Gide, para quien el Magreb fue una fuente de remozamiento erótico y literario; pero este escritor nunca se ocupó con seriedad del Islam. Para el autor de El regre- 
so del hijo pródigo, el libro del desierto por excelencia sigue siendo la Biblia. Lawrence de Arabia llevó considerablemente más lejos su metamorfosis, aunque se apoyaba en consideraciones de tipo político, y las vicisitudes de la historia contemporánea abortaron su vocación.

Sin duda, el verdadero padre espiritual de Isabelle Eberhardt es aquél que el mundo musulmán, en el momento de escribir estas líneas, aún venera con el nombre de Muhammad Asad. Nació en 1900 en el ghetto en la ciudad de Low, en Galitzia oriental. ${ }^{3}$ Su nombre era entonces Leopold Weiss. En 1922, cuando trabajaba como periodista en Berlín, descubre por primera vez Egipto y Palestina. Sabe que en lo sucesivo formará parte, en cuerpo y alma, del mundo árabe. Su nueva vida comienza durante los seis años que pasa al lado de Ibn Saoud, y culmina con la creación de Pakistán -zona islámica del subcontinente indio, del que será su primer representante ante la ONU. Lo conocí en Tánger, donde se había retirado para preparar una nueva traducción inglesa comentada del Corán.

Sin embargo, Muhammad Asad, político, místico y teólogo, no escogió la literatura como ideal de vida. En este sentido está más cerca de Isabelle Eberhardt un escritor francés contemporáneo, prematuramente desaparecido, François Augiéras (1925-1971). Inmediatamente después de la última guerra, André Gide recibió una serie de breves escritos que consideró "sobresalientes entre todos", y que aparecieron en 1954 en las Editions de Minuit con el título Le Vieillard et l'enfant. El nombre del autor, Abdallah Chaamba, armonizaba muy bien con el relato en primera persona de ese niño africano que vive en casa de un oficial francés jubilado, en un oasis del Sáhara. La evocación de la miseria y del esplendor de la vida cotidiana en el Sáhara confiere a esa escritura desmañada un tono de aspereza y de verdad incomparables.

El misterio que rodeaba a Abdallah Chaamba se disipó por desgracia el día en que apareció, en 1964, Une adolescence, au temps du Maréchal (editado por Bourgois). Este relato autobiográfico extremadamente conmovedor y delicioso (por ejemplo, el episodio en casa del pintor Roger Bissière) esclareció, como se dice, el caso de Le Vieillard et l'enfant. De ello resultaba,

\footnotetext{
${ }^{3}$ Muhammad Asad, Le chemin de La Mecque, Edit. Fayard.
} 
sobre todo, que los años magrebianos de Augiéras sólo habían sido una aventura sin porvenir y que su metamorfosis en Abdallah Chaamba se interrumpió bruscamente. Lástima. Sin duda la inspiración africana añadía una dimensión singular a la obra de este escritor. Sus obras puramente "francesas" - L'apprenti sorciere, en especial-, por muy interesantes que sean, sólo nos mueven a lamentar que no haya vuelto sobre sus pasos.

Isabelle Eberhardt, al contrario, habría "quemado sus naves" de no ser porque, para fortuna nuestra, siguió expresándose en francés. Su obra todavía espera una edición crítica que la saque del caos y del olvido que la amenaza. Cierto, el editor Fasquelle ya ha publicado tres obras: una novela, Le Trimardeur, las Notes de route y una recopilación de crónicas, Dans l'ombre chaude de l'Is$l a m$, firmadas por ella y por Victor Barrcand. Asimismo, Mes joumaliers apareció en las Editions de la Connaissance. 